\title{
The development of an ecological-economic substantiation algorithm for BAT selection for enterprises within the power industry
}

\author{
M. Berezyuk ${ }^{1}$, A. Rumyantseva ${ }^{1}$, J. Merzlikina $^{2}$ \& D. Makarova ${ }^{2}$ \\ ${ }^{I}$ Department of Environmental Economics, \\ Ural Federal University, Russia \\ ${ }^{2}$ Department of Water Resources Management, \\ Russian Research Institute for Integrated Water Management \\ and Protection, Russia
}

\begin{abstract}
The Russian Federation is on the verge of crucial changes in the system of governmental regulation for the protection of the environment. A new system of setting the norms for an acceptable impact upon the environment that provides for the rejection of individual permissions for each enterprise and the introduction of norms and plans for the gradual reduction of pollution to the levels corresponding to the best available technologies (BAT), the establishment of the advanced industry of waste disposal and the extended application of renewable energy sources are the main directions of this reforming.

The objective of this paper is to develop an algorithm for ecological-economical substantiation for the BAT application of enterprises within the power industry. The obtained results have enabled the formulation of recommendations on the assessment of expenditures for the substantiation of appropriateness of a concrete BAT application, whilst taking into account its ecological/economical effectiveness. This will enhance the validity of managerial solutions concerning the adoption of these technologies at power industry enterprises. This will lead not only to the stable decrease of an adverse impact volume but also to the increase of Russian enterprises' competitive capacity.
\end{abstract}

Keywords: power industry, algorithm, best available technologies, cost, environmental impact alternatives. 


\section{Introduction}

High levels of negative impacts upon the environment and consequently the low quality of the environment in the Russian Federation have remained stable for many years. Russia exceeds the European countries' average indicators concerning the volumes of exhaust, discharge, waste production and water/power consumption per ton of a finished commodity.

Power industry enterprises are responsible for a considerable and specific contribution to the pollution levels. In the near future a number of plants are to adopt the best available technologies in the framework of the application of the technologic norms setting system.

\section{Power industry contributions to the environmental pollution level of the Russian Federation}

In 2012 electrical power production in Russia was 1 trillion 53.9 billion kWh. Table 1 presents the dynamics of electrical power production in the Russian Federation in terms of the power station types over the past decades.

Table 1: Electrical power production in terms of the power station types (billions of $\mathrm{kWh}$ ) [1].

\begin{tabular}{|l|c|c|c|c|c|c|c|}
\hline & 1990 & 1995 & 2000 & 2009 & 2010 & 2011 & 2012 \\
\hline $\begin{array}{l}\text { All power stations, } \\
\text { including: }\end{array}$ & 1082 & 860 & 878 & 992 & 1038 & 1055 & 1054 \\
\hline thermal stations & 797 & 583 & 582 & 652 & 699 & 714 & 648 \\
\hline hydro power stations & 167 & 177 & 165 & 176 & 168 & 168 & 155 \\
\hline nuclear stations & 118 & 99,5 & 131 & 164 & 171 & 173 & 177 \\
\hline
\end{tabular}

Power consumption in the RF in 2012 increased by $1.7 \%$ in comparison with the analog indicator of 2011 and was 1 trillion 38.1 billion $\mathrm{kWh}$. The figure was given in the materials of OAO "System operator of the power grid of Russia" (CO ЕЭС). At this, power consumption in Russia in 2012 was 1 trillion 16.3 billion $\mathrm{kWh}$, a $1.6 \%$ increase in comparison with 2011.

Analysis of statistical data on the adverse impact upon the environment components shows that power industry of the Russian Federation is among the three leaders in terms of the exerted influence volume. Thus, in 2012 the volume of exhaust in the atmosphere was 4.2 million tons of pollutants; the volume of water consumption was over 27 billions of cubic meters, some 1 billion cubic meters of this was polluted waste water; as for the waste production, mining was responsible for more than $92 \%$ of impact, whilst the share of power, natural gas and water production and distribution was only $0.5 \%$ of the total volume, approximately 0.03 billion tons of solid production and consumption waste [2].

Planned performance for the decrease of the branch's harmful impact upon the environment has been developed within the framework of the Power Strategy of Russia for the period of up to 2030 (confirmed by the Governmental Decree No. 17-15-p, dated November 13, 2009) (Table 2) [3]. 
Table 2: Planned control figures for decrease of the volume of power industry's negative impact on environment.

\begin{tabular}{|c|c|c|}
\hline $1^{\text {st }}$ stage: $2010-2015$ & $2^{\text {nd }}$ stage: $2016-2022$ & $3^{\text {rd }}$ stage: $2023-2030$ \\
\hline \multicolumn{3}{|c|}{$\begin{array}{l}\text { Reduction of specific indicators of the pollutants' discharge to the atmospheric air, } \\
\text { polluted waste water discharge to water bodies, waste production by power stations, at } \\
\text { least (\% to 2005) }\end{array}$} \\
\hline 25 per cent & 40 per cent & 50 per cent \\
\hline \multicolumn{3}{|c|}{ Provision for the greenhouse gases emission level, at least (\% to 1990) } \\
\hline 83 per cent & 90 per cent & 105 per cent \\
\hline
\end{tabular}

\section{Transition to technological norms setting}

The main direction of the environmental protection state regulation system reforming is the transition to a new system of setting norms of admissible impact. This new system stipulates for the rejection of the issue of individual permissions for each enterprise and the introduction of norms and plans of the staged decrease of pollution to the levels corresponding to the BAT, the establishment of an advanced industry for waste utilization and the expanding of renewable energy use.

The basis for the current system of normalizing of impact upon the environment was formed in the 1980s and was in force up until now.

A fundamental document that contains the essence of the changes is Federal law draft No. 584587-5 [4]. The draft stipulates for the preparation of 20 regulations that are to be completed before 2014 .

The following changes to the current system of regulation concerning environmental protection are principal:

- categorizing of units according to their potential danger to the environment and administration to them adequate measures of governmental control and introduction of registration of units negatively influencing the environment;

- introduction of the system of technological norm setting in respect to the units

related to the sphere of BAT application;

- development and adoption of information/engineering reference books on

BAT;

- transition from individual permissions for discharges, exhaust, and disposal of

waste to integrated permissions and declarations of reporting;

- reduction of the list of matters to be regulated;

- application of incentives for the upgrading of production.

The idea is that enterprises are to be divided into several groups with respect to the degree of their negative impact upon the environment: considerable impact, moderate impact, insignificant impact and minimal impact. For the category of ecologically dangerous enterprises there are plans for transition to the normalizing system based on BAT, taking into account an experience accumulated in the EU countries.

The changes in the Russian ecological policy are founded on the principles and provisions of the ecological normalizing system introduced in European 
Union by the EU Council Directive No. 96/61/EC dated September 24, 1996 "On the integrated control and prevention of pollution". The EU Research Center in Seville with participation of some experts developed 33 reference documents to facilitate implementation of the above directive during the period from 1997 to 2006.

The most prominent for the power industry enterprises is a reference book on BAT for large combustion plants with thermal power higher than 50 megawatt (Reference Document on Best Available Techniques for Large Combustion Plants (BREF LCP) [6]), that was developed for several years and was adopted in July 2006. The reference book contains the description and control figures of power and ecological effectiveness of the BATs used at the power industry units. In 2009 the reference book was translated into Russian [7].

From 2002 to 2012 a number of projects were performed to adopt some basic principles of the BAT approach:

- "Harmonization of ecological standards" (2002-2009). The EU and RF requirements concerning issue of permissions for exhaust, discharge and waste disposal were reviewed; a concept of the BAT application was considered; some EU reference documents were translated into Russian;

- "Reference book on the best available engineering methods for increasing effectiveness and mitigation of negative impact on environment in thermal power production industry" was translated (2008);

- "Main provisions (Concept) of engineering policy in electrical power industry for the period till 2030" [8] (financed by OAO RAO "UES of Russia");

- Information digest "Modern nature/protective technologies in electrical power industry" [9].

The Concept [8] formulated the main aims and tasks of the engineering policy in the context of the target-oriented vision of the power industry development strategy for the period till 2030, described the policy in the sphere of electric power systems, heat-and-power engineering, heat supply, hydro power engineering and water-work facilities, RES, electric power equipment [9].

The planned stages of transition to the technological norm setting system are presented in Table 3.

Table 3: Stages of transition to the technological norm setting system [5].

\begin{tabular}{|l|l|}
\hline Stage & \multicolumn{1}{c|}{ Output } \\
\hline $\begin{array}{l}\text { Before } \\
2017\end{array}$ & $\begin{array}{l}\text { development of all necessary documentation: division of enterprises by } \\
\text { categories, preparation of regulations, confirmation of plans of measures } \\
\text { aimed at mitigation of impacts, development of reference books on BAT }\end{array}$ \\
\hline $\begin{array}{l}\text { Since } \\
2017\end{array}$ & $\begin{array}{l}\text { introduction of the ban on designing of new enterprises inconsistent with } \\
\text { the BAT principles }\end{array}$ \\
\hline $\begin{array}{l}\text { Since } \\
2019\end{array}$ & $\begin{array}{l}\text { it is planned to forbidden commissioning of new plants whose discharge } \\
\text { and exhaust are inconsistent with BAT, excluding plants that managed to } \\
\text { receive the permission prior to the change of the legislation }\end{array}$ \\
\hline $\begin{array}{l}\text { Since } \\
2021\end{array}$ & administrative restrictions will be applied to all the enterprises \\
\hline
\end{tabular}




\section{Application of the algorithm: problems and the ways of solution $[11,12]$}

In practice the uncertain situations may occur when determining BAT: it might be unclear as to which technique would provide the highest level of environmental protection. Therefore, it is necessary to make a preliminary assessment of techniques to identify the best one.

The authors propose a several stage algorithm for selection of BAT by power industry enterprises.

\subsection{Ecological effectiveness of BAT application}

Stage 1. Analysis of the current state of the enterprise. It is necessary to assess the current state of the enterprise in terms of its impact on environment. First of all, environmental pollution at power stations depends on techniques used at the station and on the type of fuel used for the power production.

Power stations can be classified by several attributes:

- by the type of production processes: thermal, nuclear, and hydro power stations. According to the Ministry of Energy data, the generating supplies are distributed as follows: thermal power stations produce $68.4 \%$ of the total power production, hydro power stations produce $20.3 \%$, and nuclear power stations produce about $11.1 \%$. In practice, the main share of pollution is contributed by thermal power stations;

- by the type of the consumed fuel. This characteristic is to help to find out presence of this or that discharges/exhaust of industrial waste;

- by the volumes of negative impact on the environment.

On the basis of volumes of the enterprises' impact on the environment components it is necessary to determine its category of hazard from the ecological point of view [4]. According to the impact indicators' combination it is necessary to determine whether this particular enterprise's impact is liable to regulation in respect of BAT. Mostly plants that considerably affect environment are to be regulated by the legislation on setting norms according to BAT.

At present there are no clear enough criteria (defined by legislation) to guide relating an enterprise to a certain category. Experts consider various factors to be taken into consideration in order to establish a system of indicators: volume of power production, volume of fuel consumed, regional importance of this enterprise at the local territory.

Stage 2. Determination of the area of alternative techniques application. At this stage it is necessary to consider all techniques that can be used in order to decrease the extent of impact on environment; their criteria and results of their application are presented in Table 4. At that preference may be given to existing techniques that are able to prevent or reduction of pollutants' discharges (emissions) to environment in case of their updating or to novel techniques that will affect environment to the least extent. 
1166 Energy Production and Management in the 21st Century, Vol. 2

Table 4: Alternative criteria for the assessment of techniques for power production stations.

\begin{tabular}{|c|c|c|}
\hline $\begin{array}{c}\text { Area of } \\
\text { application }\end{array}$ & Criteria & $\begin{array}{l}\text { Results of } \\
\text { application }\end{array}$ \\
\hline $\begin{array}{l}\text { technological } \\
\text { solution }\end{array}$ & $\begin{array}{l}\text { upgrading of processes, equipment, a station; } \\
\text { supplement of the technological process with } \\
\text { alternative means of power production based on } \\
\text { the use of production by-products }\end{array}$ & \multirow{6}{*}{$\begin{array}{l}\text { - reduction/ } \\
\text { stoppage of } \\
\text { discharges } \\
\text { and } \\
\text { emissions; } \\
\text { - reduction of } \\
\text { raw material/ } \\
\text { water, etc. } \\
\text { consumption; } \\
\text { - decrease of } \\
\text { waste volume; } \\
\text { - decrease of } \\
\text { the used land } \\
\text { area }\end{array}$} \\
\hline $\begin{array}{l}\text { choice of raw } \\
\text { material }\end{array}$ & $\begin{array}{l}\text { cleaner fuel, possibility to use accumulated } \\
\text { waste of raw material mining, production and } \\
\text { consumption (waste recycling) }\end{array}$ & \\
\hline $\begin{array}{l}\text { production } \\
\text { processes control }\end{array}$ & optimization of the power production process & \\
\hline $\begin{array}{l}\text { organizational } \\
\text { measures }\end{array}$ & $\begin{array}{l}\text { modes of purification, optimization of the } \\
\text { equipment operation, and maintenance }\end{array}$ & \\
\hline $\begin{array}{l}\text { non-engineering } \\
\text { measures }\end{array}$ & $\begin{array}{l}\text { training of personnel, organizational changes, } \\
\text { application of ecological management system; } \\
\text { intensification of innovative activity of all } \\
\text { levels of employees }\end{array}$ & \\
\hline $\begin{array}{l}\text { "at the pipe end" } \\
\text { technology }\end{array}$ & $\begin{array}{l}\text { installation of equipment for waste recycling, } \\
\text { waste incineration, and waste water treatment }\end{array}$ & \\
\hline
\end{tabular}

When determining the area of alternative techniques application the parameters of the versions to be considered should be defined. Ideally, assessment should be done for techniques with the same parameters for the end product. Otherwise, any differences are to be revealed to prevent distortion of the results. If there is no adequate data to make a choice and there is a doubt concerning the particular version that can secure the highest level of protection for environment, it is expedient to pass on to the next stage.

Stage 3. Analysis of alternative techniques. Analysis and summing up of data on pollution emissions (discharges, production/consumption waste formation) as the results of application of each of the considered techniques, as well as the analysis of the consumed resources should be performed. It is necessary to present, as a list (with quantitative indicators), significant input and output parameters of the considered techniques. This list should include the produced discharges, emissions, waste, other impacts, and consumed raw materials (water, coal, natural gas).

The following kinds of data can be the source of information: monitoring data, obtained at the similar facilities; reported data of the given enterprise; data of the researches being conducted; design laboratory data; information of purveyors and equipment manufacturers; data of information exchange.

Data should be as complete as possible, exact and objective. It is necessary to take into consideration both organized and unorganized sources of impact, and to secure detailed elaboration of the obtained data and documentation of the data sources. 
Stage 4. Assessment of all kinds of impact upon environment. In terms of each of the considered alternative technologies, comparisons of different pollutants for seven priority ecological problems are to be made: 1) toxicity for people; 2) toxicity for water bodies; 3) global warming; 4) acidic precipitation formation; 5) euthrophication; 6) depletion of ozone layer; 7) probability of tropospheric ozone formation.

At this point, the contribution of individual pollutants can be computed with the use of special indices and converted into equivalents.

When accounting for each particular matter, attention should be given to the following:

- assessment of the considered technique contribution to the total input of the

pollutant;

- quality of environment;

- presence of sensitive recipients;

- character of consequences of impacts upon environment;

- pollutants characterized by high stability are to be considered as priorities.

It is obvious that the main indicators that characterize each power plant contribution to the situation improvement or deterioration according to each of the versions should be reflected. This stage should be supplemented with the forms suitable for filling, and the list of information sources.

Stage 5. Description of an approach to (method of) environmental problems assessment. Three possible approaches to the assessment of the versions and to obtaining of results on the basis of the assessments made are proposed. Each of these approaches can be used independently or together:

1) it gives a comparison of the previously considered and computed impacts for each of the seven environmental problems;

2) it enables the comparison of contributions made by the techniques to be considered to each out of the seven environmental problems with common European reference indicators;

3) it enables the comparison of individually considered pollutants with the data of the European register of pollutants emissions and discharges.

The said approaches enable to arrange information in a transparent enough mode, this is, undoubtedly, necessary for correct comparison of the alternative techniques. At the same stage a need to rank priorities in respect of the main environmental problems or even individual pollutants may occur.

In the process of BAT determination for a power industry enterprise all the relevant local issues are to be taken into account in details: climatic and logistics, specific features of location, as well as prospects of social/economic development of the territory while taking into account the outlook of governmental and private investing.

Stage 6. Analysis of additional available information in order to describe alternative techniques. At this stage all additional available information would be determined. It is needed for elaborated description of techniques and determination of positions concerning technical characteristics of the alternative 
techniques: technical and economic life term of equipment, operational data (operation regulations, consumption of fuel, power, water, etc.).

Advantages in terms of the extent of impact on the environment that would be reached in case of these techniques application also can be described at this stage. It is helpful to compare these environmental advantages with the current situation (the basic version) or an expected version. Together with the impact level it is necessary to estimate the degree of reliability of the considered production systems performance for the given terrain (in respect of irregular impact on the environment components, probability of emergency situations with high level of damage/casualties among civil engineering facilities and population), and to compare the supposed reliability with the basic version.

Registration of data on the compared indicators can be performed by two methods; in relative or absolute values.

After considering and ranking the possible options from the point of view of environmental effectiveness, the option with the least impact upon environment is to be adopted as the best one, only, however, in the case of its economic feasibility.

\subsection{Economic effectiveness of BAT application}

Stage 7. Collection of data on techniques' application cost. First it is recommended to state the order of actions necessary to collect, analyze and substantiation of all available data on costs.

As these data on costs can be received from various sources one should critically enough assess their reliability. It is necessary to take into account all factors that could affect the data authenticity. No doubt, it can affect the output of assessment and the final decision on the BAT choice.

The main sources of data on expenditures are the following: producers (suppliers) of the technique and equipment; consultants and research teams; plans of the power industry development; authorities; published information (reports including reports of power experts, sites of power industry plants, and proceedings of conferences); estimation of costs in comparable projects of other industries.

To secure validity of data it is important to collect information from several independent sources. It is important that: a comprehensible source of information; completeness of the presented data; independence of the information sources; exactness of data registration; the latest available data; date of collection and receiving of data; the range of quantitative indicators.

Assessment and maximal reduction of the information uncertainty are important. Reliability of the used information at the different stages of the project formation is increasing due to selection of one-type data and reliable, checked sources as well as expert assessment. Besides, impression of costs in prices of the same period and in the same currency is a prerequisite.

Stage 8. Determination of the composition (structure) of the techniques application cost. The expenditures necessary for assessment of techniques are to 
be determined. The main objective of this stage is to identify costs elements to included or excluded from assessment.

It is possible to distinguish the following groups of expenses: 1) investment; 2) annual expenditures for operation and maintenance - operating costs; 3 ) costs to be considered separately.

The basic version is to be set according the BAT assessment methodology, while the alternative versions are considered relatively the basic version. Expenditures for all versions are to be shown for construction of new power plants.

It is recommended to divide the data on costs into separate components within the framework of each group of costs. This must be done to maximal possible extent to develop an estimate of expenditures:

1. Investment

1.1. Expenses for installation (facilities, equipment)

1.2. Expenses for nature/protective equipment

1.3. Incidental expenses

2. Operating/maintenance costs

2.1. Costs of energy carriers

2.2. Costs of materials and services

2.3. Costs of labor

2.4. Expenditures for repair and maintenance of equipment

2.5. Overhead costs

2.6. Follow-up costs

3. Costs to be considered separately

Stage 9. Assessment of revenue. At the individual stage it is necessary to collect information on additional incomes that might occur during the BAT application. If the considered alternative versions can lead to obtaining of incomes and benefits of non-environmental character or to saving of certain expenses, they are to be listed separately from investment and operating costs. Income from selling, prevented expenses and subsequent benefits relate to such kinds of revenue.

1. Income from sale: sale of treated waste waters; sale of ash-and-slag waste; sale of additionally produced electric power.

2. Prevented expenses: saving of raw materials and main materials; saving of auxiliary materials; saving of labor expenses; saving on emission (discharges) monitoring; reduction of emission (discharges); reduction of payments for emission (discharges); reduction of indirect costs for environment component quality restoration; reduction of indirect costs for the public health rehabilitation and related losses in production.

3. Subsequent benefits. Application of a novel technique can cause changes in the production process which, in turn, can lead to production costs reduction or to the higher quality of results. As possible, it is necessary clear identify and assess the obtained benefits and include them into data on revenue.

Stage 10. Processing and presenting of information on costs and benefits. It is necessary to process the collected information on costs and benefits in such a way that it will be possible to compare objectively the alternative versions. At 
that, consideration of such issues as different terms of the equipment service, making expenses and obtaining of outputs in different periods of time, influence of negative factors, etc. can appear to be necessary. The used methods of costs/benefits information processing should be accessible and easy to understand; here some freedom of choice occurs. A user should validate its choice and to secure competence and transparency of computations.

Thus, it is possible to formulate the most significant moments concerning processing and presenting of information: 1) provision of calculations and reporting of data a annual costs and incomes; 2) reduction of funds flow to a unified currency (rubles in the Russian Federation); 3) taking inflation into consideration; 4) presenting of initial data in the prices of the basic year; 5) usage of real prices in calculations; 6) the use of the funds flow discounting method; 7) a validated approach to determination of the discount rate.

To assess investment and operating costs the conditions of calculations will be considered similar within the framework of the single legislation/regulations action at the national (international) level. It is necessary to take into account the differences in economic calculations in EU member states or other states to validate application of the appropriate BAT in the conditions of the Russian Federation.

In order to take into consideration any regional differences in economic indicators of costs for performance of building and assembly works, cost of raw materials it is necessary to be guided by the requirements of regulatory/methodological documentation of the Russian Federation for the sphere of civil engineering.

To take into account regional differentiation in the producers' price changes indices it is necessary to follow official statistic data of the Federal Service of State Statistics concerning changes of prices in the economy branches depending on the regional factor. The used indicators and their respective sources should be clearly indicated in the project substantiation.

In assessment of costs the data should be divided according the following:

1) investments into technological processes and equipment to be used exclusively in order to reduce/prevent negative impact upon environment ("at the pipe-end technology");

2) investments into processes and equipment that can be used for other objectives, connected, for instance, with power saving or minimization of waste and that can give commercial benefits and compensate some expenses (this projects may include equipment for reduction of water use). Meanwhile the total volume of financial resources cannot be attributed exclusively to protection of environment as there are other benefits (for instance, increase of productivity or improvement of commodities' quality).

Stage 11. Assessment and comparison of alternative techniques. After stating benefits for environment and economic costs of these versions' implementation it is necessary to make a comparative analysis and determine which technique is consistent with the BAT criteria. Economic effectiveness, undoubtedly, is critical in identification of the BAT and in this aspect it is necessary to find out which 
one out of the considered techniques warrants the greatest environmental benefits accompanied with the least financial costs. Several means of determining economic efficiency can be identified: analysis of economic efficiency; distribution of costs between polluting emission (discharges); comparison of costs for the technique application and benefits for environment.

\section{Conclusions}

Experience in the BAT development and application at thermal power stations of the European Union witnesses the fact that application of BAT should be supported and secured by a set of financial and organizational measures, state support, engineering/scientific programs for development and application of novel environmentally-friendly techniques of power production as well as effective system of regulatory/methodological documents.

It is necessary to intensify the process of nature/protective sector upgrading to reduce risks of enforcement of the new normalization system at power industry plants. It is recommended to use methodology of the BAT assessment adapted for the conditions of the Russian Federation in order to choose versions of modernization, reconstruction, and new construction of nature/protective facilities.

The developed algorithm of the BAT choice for the power industry plants is an adapted provisions of the methodology presented in European reference books [11]. The algorithm states have been supplemented with the recommendations on practical application of the main principals and requirements of a methodology for Russian power industry plants and they contain:

- recommendations on hazard category assessment from the environmental point of view, as well as power industry plants' volume of impact on environment components;

- recommendations on taking into consideration regional differentiation in the producers' price changes indices when calculating costs for the BAT application.

\section{References}

[1] Electricity production by type of power, [in Russian], Russian Statistical Yearbook, the Federal State Statistics Service, Moscow, 2012. http://www.gks.ru/bgd/regl/b12_13/Isswww.exe/Stg/d3/13-50.htm.

[2] Environmental protection. Russian Statistical Yearbook, [in Russian], the Federal State Statistics Service, Moscow, 2012. http://www.gks.ru/ bgd/ regl/b12_13/ Isswww.exe/Stg/d3/13-50.htm.

[3] Russian Federation Government Order of November 13, 2009 N 1715-r "On the Energy Strategy of Russia for the period up to 2030", [in Russian], Reference Legal System Consultant Plus, 2013. http://www.consultant.ru/_document/cons_doc_law_94054/

[4] Draft of Federal Law of October 7, 2011 N 584587-5. "On Amendments to some legislative Acts of the Russian Federation in terms of improving 
standardization in the field of environmental protection and the introduction of economic incentives for business entities to introduce the best technology", [in Russian], Reference Legal System Consultant Plus, 2013.

http://base.consultant.ru/cons/cgi/online.cgi?req $=$ doc;base $=P R J ; n=88295 ; \mathrm{d}$ $\mathrm{st}=0$.

[5] Yurmanova, S.V., Directions for improving regulation and economic incentives, [in Russian], Industrial Ecology, 8, pp. 17-22, 2013.

[6] Reference Document on Best Available Techniques for Large Combustion Plants. European Comission, 2006.

[7] Handbook on best available techniques for large fuel combustion plants (transl.), [in Russian], SE "INVEL", 2009.

[8] Basic Provisions (Concept) technical policy in the power industry of Russia until 2030, [in Russian], OAO RAO “UES of Russia”, 2008.

[9] Abramov, V.V. et al., Modern technologies in power industry: Information digest, edit. V.Y. Putilov, [in Russian], MEI Publishing House: Moscow, 2007.

[10] Saparov, M.I., et al., Best available technologies - modern tool to improve energy efficiency and reduce the negative impact on the environment from power enterprises. Proceedings of the all-Russian scientific-practical conference "Improving the reliability and efficiency of operation of power plants and power systems. Energy - 2010 \& MEI Publishing House: Moscow, т.2, pp. 235-238, June 1, 2010.

[11] Economic aspects and impacts on different components of the environment. Reference Document on Best Available Techniques, [in Russian], Project "Harmonisation of environmental standards HES II, Russian”. 2006. http://14000.ru/brefs/BREF_ECME.pdf.

[12] Sokornova, T.V., Koroleva, E.B., Sergienko, O.I \& Kryajev, A.M., Economic aspects of the implementation of BAT, [in Russian], Industrial Ecology, 10, pp. 28-35; 11, pp. 44-49, 2012.

[13] Statistics of power industry sector, [in Russian], Ministry of Energy of the Russian Federation.http://minenergo.gov.ru/activity/powerindustry. 